\title{
Ambient Task with Stimulus-Response Compatibility Concept for Guiding Alzheimer's Actions
}

\author{
N. W. Basharudin, Ku Azir K.N.F, P.Ehkan, A. M. Khairuddin \\ Embedded, Networks and Advanced Computing Research Cluster (ENAC), \\ School of Computer and Communication Engineering, Universiti Malaysia Perlis (UniMAP), Perlis, Malaysia
}

\begin{abstract}
Article Info
Article history:

Received Apr 9, 2018

Revised May 20, 2018

Accepted Jul 11, 2018

\section{Keywords:}

Stimulus-response compatibility

Ambient Intelligent

Stroop task

Alzheimer's disease

Flashcard game

ABSTRACT

Alzheimer is one of the diseases that can cause the patient to act in different and unpredictable ways. This disease destroys memory and thinking skills and, eventually, the ability to carry out the simplest tasks. Advanced in technology actually can help them be more independent doing their routines. Hence, this study was conducted to investigate the relationship between stimulus-response compatibility (SRC) and ambient intelligent elements for Alzheimer's patients. The aim of this study is to obtain a strong answer on how ambient elements (stimulus) such as ambient colours, lights and pictures can assist Alzheimer' patients in daily living activities. For this reason, we developed a flashcard game based on ambient colours and pictures to achieve two objectives which are (i) to test the ambient's factors that highly effect the responses of Alzheimer's patients and (ii) to observe the response towards the given instructions. This experiment has been tested to 10 participants with mild-stage of Alzheimer's disease. The findings of this experiment show that the patient response more towards ambient colours compared to the ambient pictures. $90 \%$ of respondents capable to complete the task correctly and quickly based on ambient colours. In addition, the experiment proved that the participants have no difficulty in order to understand the instructions given to them for completing the tasks smoothly.
\end{abstract}

Copyright $\odot 2018$ Institute of Advanced Engineering and Science. All rights reserved.

\section{Corresponding Author:}

N. W. Basharudin,

School of Computer and Communication Engineering,

Universiti Malaysia Perlis (UniMAP),

Perlis, Malaysia.

Email: nurwaheeda1008@yahoo.com

\section{INTRODUCTION}

The total population of Malaysia is estimated at 31.7 million persons recorded by Department of Statistics Malaysia until 2016 [1]. Distribution of population by age group showed population aged 65 years and above was increased by $0.2 \%$ for 3 years since 2014 [1]. The statistic also recorded that senior citizens aged 60 and above made up 2.8 million or 9\% of Malaysia's population of 31 million until 2015 [2].

Dementia is probably one of the more feared illnesses of old age. As the number of senior citizen increases, the disease also increases such as Alzheimer. Those people over the age of 65 and 80, from 5\% and $20 \%$ of them respectively have a risk of getting cognitive impairment. This disease causes patients experienced short-term memory loss. As time goes on, the person's ability to remember, reason understand and communicate will progressively decline. Their memory loss may result in them forgetting to perform routine activities like eating or cleaning up or insisting on doing these activities repetitively because they have forgotten they have already done them. Therefore, the percentage of senior citizens with Alzheimer's disease relying on people around them is increasing due to they're incapable to handle routine activities by themselves. Women, Family and Community Development Minister said the government has been making 
various preparations to ensure this group of senior citizens would still be healthy, productive and able to contribute to society. One of the ways to support themselves is through ambient assisted technology.

Ambient intelligent can be defined as a sensitive and adaptive environment towards the action of people and object and cater their needs. Ambient assisted living (AAL) technology can focus on developing an intelligent environment for monitoring routine activities of Alzheimer's patients by using the ambient intelligent. Ambient intelligent is the tremendous solution for supporting people such as Alzheimer's patients living independently in the home by becoming sensitive and adaptive environments towards the actions of people and objects and cater their daily needs ambient technologies assisted living user's activities by capturing and monitoring the daily activities that provide non-intrusive and privacy-friendly.

In this work, we describe an experiment of implementation of ambient intelligent elements with stimulus-response compatibility (SRC) concept. SRC refers to actions performing by people is more accurate and quick when mappings of stimuli to responses are concurrent than when they are non-concurrent [3]. This work conducted based on two objectives which are (1) is to identify either ambient colours or ambient pictures give high influenced towards Alzheimer' actions while the (2) is to analyze the level of understanding against instruction delivered to patients in order to complete the task. These objectives had verified with simple flashcard game model consisting a combination of ambient colours and ambient pictures which is functioning to observe the relations between displays and controls which is the reaction of patients based on a specific instruction given. The idea of creating this experiment is inspired by developing a current user-friendly environment with applying ambient technology to assist Alzheimer' behaviours in a certain situation. These ambient intelligent elements are tested in the kitchen workspace.

The kitchen becomes the main focus because it is where many activities that are key to autonomy performed as kitchen involved tools, actions and multiple activities at the same time. Such as cooking while washing cloth and cooking while baking, these multiple activities can create possible wrong actions which will lead to the proposedly accident. Therefore, with the ambient light it is expected that when it been implemented in the kitchen, it can recognize possible unwanted actions. For example, misapplication of a spoon to break ice cubes while it is actually for food feeding or scoping purpose, another misapplication uses a knife as can opener cover while it is for cutting purpose. Ambient technology also approaches based on artificial intelligence techniques to distinguish an abnormal activity in the kitchen.

This paper has presented the SRC concept and ambient elements that had applying in the flashcard game for Alzheimer's patients. The fundamental of Stroop task study had implemented in flashcard game. The final result demonstrated ambient colours highly influenced actions of patients, leading to much faster and accurate responses. The benefit of this study is to get strong confirmation that the ambient elements can help the patient in guiding them to complete a particular activity. Next, will encouraging patients be more independent at home especially in the kitchen with ambient intelligent technology.

\section{RELATED RESEARCH}

The uses of AAL for monitoring activities and assisting a human in the smart environment have attracted tremendous research interests in recent years. AAL provides important development of innovation in information technology that should be can improving the quality of life and autonomy with the smart environment in house, office, vehicle, street and shopping mall. The smart environment can help people in a wide range of tasks by learning of behaviours which are a major recent advancement in the area.

Activities of people can be monitored to detect abnormal activities to prevent undesired consequences before they become critical [4]. SmartMind is one of the systems that create for Alzheimer's patients to describe their normal living habit besides aiming to handle emergency situation happened in living room [5]. An Ambient Information Systems help elders to manage their medicine by reminding, guiding and motivating them to medicate [6].

The concept of SRC is great ideas that have many basic and applied implications for human information processing and performance. The spatial arrangement between stimulus-response (S-R) refers as compatibility when relation between displays (stimulus) and controls (response) is direct [7]. Compatibility effects has found to be influence performance in various situations such as Stroop task. Stroop task is a paradigm of the colour-word task, participants have to identify the ink colour of a colour word printed easily and quickly in time. There are two methods which are colour-word matching Stroop task (cwmStroop) and Go/NoGo tasks in a clinical test of the attention and inhibition abilities of children with developmental disorders [8]. A study of stimulus and responses conflict in colour-word Stroop task had done by combining event-related brain potentials (ERPs) and electro-myography (EMG) [9]. Stroop effect in pure blocks had used in the assessment of inhibition and goal maintenance in persons with Alzheimer's disease, mild cognitive impairment, healthy older adult and younger adults [10]. The concept of Stroop task is closely related to the flashcards experiment goal in this paper as it is involving flashcard colours and words tested. 
SRC creates naturalness of the connection between stimulus and the associated response that will contribute to the fast reaction time in compatible S-R pairs. The combination of ambient intelligent elements and SRC concept in the smart environment can create a system to assist living activities of Alzheimer's patients. Furthermore, through stimulus and response compatibility effects, we can study and analyse their behaviours patterns easily. Therefore, be prepared if any autonomous actions happened the systems will guide them back to correct and proper actions that should be performed.

\section{METHODS AND MATERIALS}

At the early stage of the research, we applied ambient flashcard game as part of monitoring purpose of Alzheimer's understanding of meaningful of colour. The purpose of using flashcard is to utilize the patients by learning the materials and keeping the information at the forefront of mind also with a little spatial testing. It is suggested, that flashcard game will be able to help patient's brain focus on the material and effectively keep it available for them to recall when the next test comes up.

The game was conducted at The Dementia Society (TDS) Perak. The participants that involved in this experiment are had mild (early-stage) Alzheimer's disease which is during this stage patient's activities and social life is disturbed due to memory troubles. There are 10 participants (average age 82 years old) participated in this experiment, with 9 of them are Chinese and 1 Malay. These include 8 male and 2 female participants. All participants have no difficulties regarding speak and move around on their own although sometimes they forgot what actually they did. They are all showing interest to participate in the experiment.

Figure 1 shows one of the participants is undergoing the flashcards experiment. In the colour-word of Stroop task, participants need to name the ink colour of word by ignoring the meaning of the word, which is they have to refer to the colours printed in a corresponding colour (the word blue printed in blue ink) or in non-corresponding colour (the word red printed in green colour). For the flashcard game, participants need to match cards of (i) picture-picture by ignoring the colour of cards; (ii) colour-colour by ignoring the pictures on the cards; (iii) picture-word (English words) by ignoring the colour of cards; and (iv) word (Malay words)-picture by ignoring the colour of cards.

The experiment took place in a quiet environment which is in the activity room of TDS. At very first, each participant was briefed and demonstrated, also instructions are given to the participants verbally by the instructor at the beginning of the experiment. For each condition, the participant had prepared to seat on the chair facing the board of stimuli pile flashcards on the table.

There are two set of model, which are the stimuli pile and the responds pile. The stimuli pile consists of flashcards which act as the stimulus for this experiment. Meanwhile the responds pile contains another and different set of flashcard which will be hold by the participants. These flashcard act as responds and ready to react accordingly to the instructions given. There are two cameras had installed from the front view and top view of the place of experiment. The front cameras for recording the expressions or body language of participants during the experiment while the camera from above is top viewing to monitor running experiments from start to finish. In addition, the time from instruction given was taken as time reaction and no specific time limitation for the participants to complete the task.

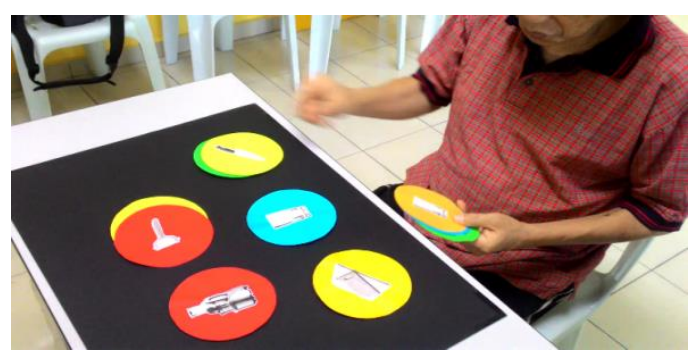

Figure 1. Participant undergoing the experiment

\section{ACTIVITY TYPE}

This game consist of specific elements which are five ambient colours; blue, red, green, yellow and orange colours while ambient pictures had two groups consist of five pictures of fruits and utensils equipment as shown in Figure 2. 


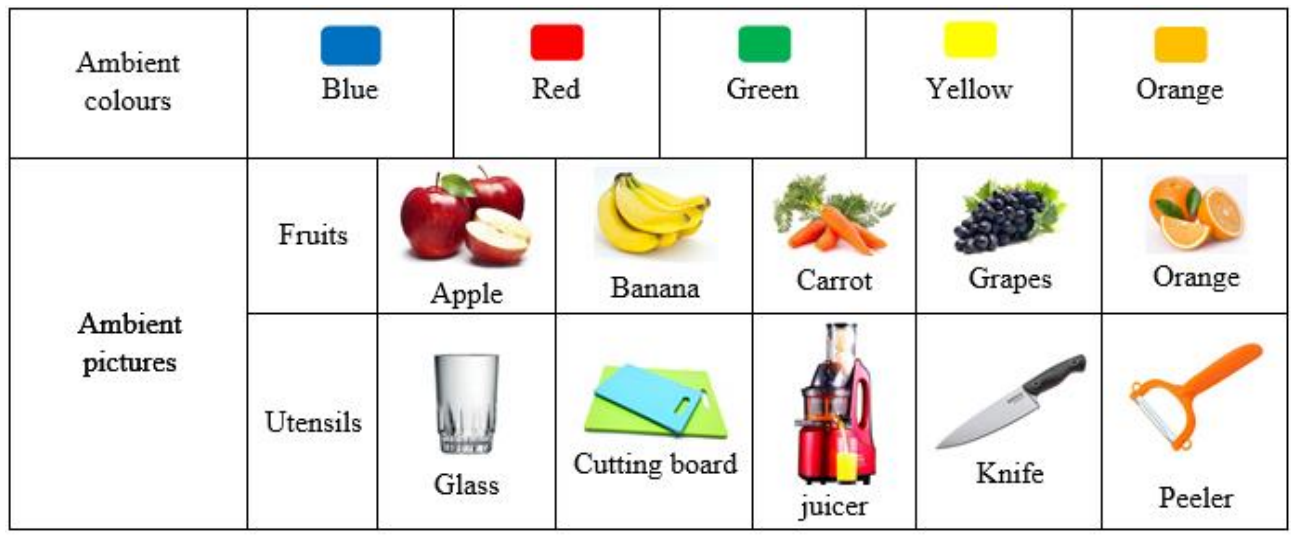

Figure 2. The ambient elements in the flashcards model

A participant needs to complete four different tasks from this experiment. Briefly, the participants require to match the responds pile to the stimuli located in the stimuli pile. All the four tasks that need to complete is as follows:

4.1. Picture - Picture: Participant is required to match the flash cards by referring picture on stimuli pile. In this task, participants require to match the responds pile of utensils pictures with the same pictures on the flashcards located inside the stimuli pile as shown in Figure 3. The purpose of this task is to observe the ability of Alzheimer's patients recognizing the picture of utensils correctly.

4.2. Colour - Colour: Participants is required to match the flash cards by referring card colour on the stimuli pile. This task required the participants to match the card of responds pile with the same colours as cards on the stimuli pile by ignoring the picture display on the card, Figure 4. It is purposed to observe either Alzheimer's patient be able to identifying colours correctly or not.

4.3. Picture - Word: Participants needs to place the flash card according of the correct name of fruits in English. Participants had asking to match the pictorial cards of fruits in responds pile to the correct cards with written word of fruit's name on the stimuli pile as shown in Figure 5. From this task, we can observe the effectiveness of participant' responses towards stimulus in the form of words.

4.4. Word - Picture: Participants needs to place the flash card according of correct picture of the fruit as shown in Figure 6. Actually, this task is inversing from the Task 3 that needs the participants to match the pictorial cards of fruits (responds pile) with written word of fruit's name in Malay on the stimuli pile.

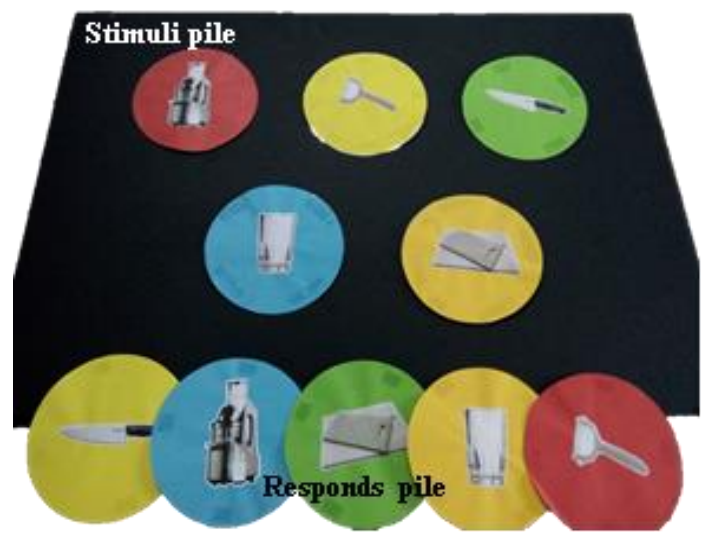

Figure 3. Task 1 - Experiment setup to match picture and picture

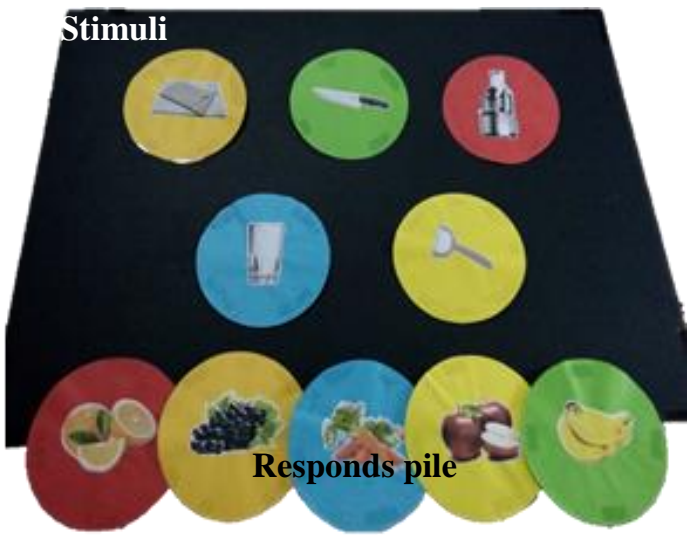

Figure 4. Task 2 - Experiment setup to match colour and colour of cards 


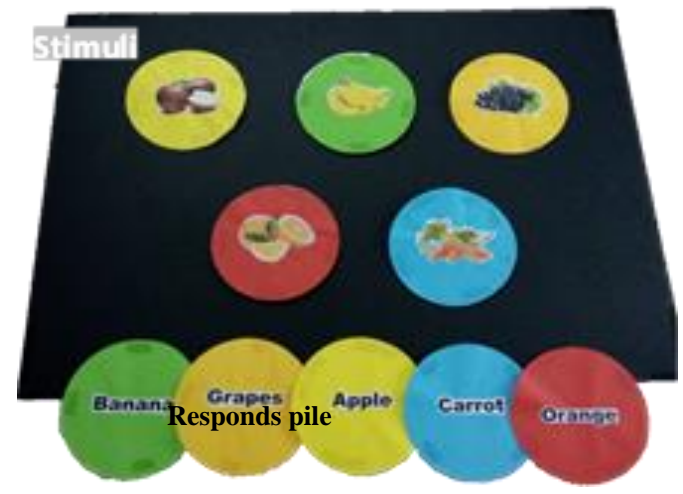

Figure 5. Task 3 - Experiment setup to match word and picture

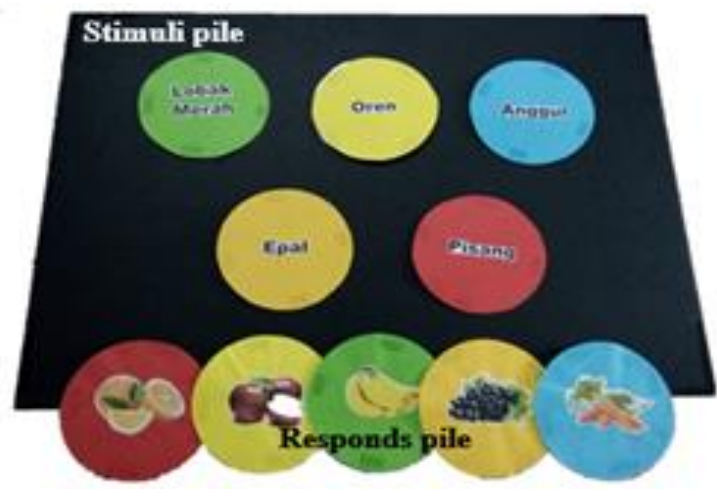

Figure 6. Task 4 - Experiment setup to match picture and word

The instruction for each task are as shows in Table 1 and the list of stimulus and possibilities responses that will react by participants for completing each instruction is listed in the Table 2 .

Table 1. Four different instructions of simple ambient task

\begin{tabular}{|c|c|c|c|c|}
\hline No. & Instructions & Match the flashcard & Stimulus & Responses \\
\hline 2. & $\begin{array}{l}\text { Do Instruction 2: Match the flashcard by referring card } \\
\text { colour on the given model. }\end{array}$ & Colour with colour & Colour card & Colour card \\
\hline 3. & $\begin{array}{l}\text { Do Instruction 3: Place the flashcard according of } \\
\text { correct name of the fruit }\end{array}$ & $\begin{array}{l}\text { Pictures with Words } \\
\text { (Fruit X name of fruit) }\end{array}$ & $\begin{array}{l}\text { Fruit } \\
\text { pictures }\end{array}$ & Name of fruits \\
\hline
\end{tabular}

Table 2. List of Stimulus And Possibilities Responses

\begin{tabular}{|c|c|c|c|c|}
\hline \multirow{6}{*}{ Instruction 1} & \multicolumn{2}{|l|}{ Stimulus } & \multicolumn{2}{|c|}{ Responses } \\
\hline & \multirow{5}{*}{ Pictures } & Peeler & \multirow{5}{*}{ Pictures } & Fruit Juicer \\
\hline & & Knife & & Knife \\
\hline & & Cutting Board & & Glass \\
\hline & & Glass & & Cutting Board \\
\hline & & Fruit Juicer & & Peeler \\
\hline \multirow{5}{*}{ Instruction 2} & \multirow{5}{*}{ Colours } & Red & \multirow{5}{*}{ Colours } & Green \\
\hline & & Yellow & & Blue \\
\hline & & Orange & & Orange \\
\hline & & Blue & & Yellow \\
\hline & & Green & & Red \\
\hline \multirow{5}{*}{ Instruction 3} & \multirow{5}{*}{ Pictures } & Grapes & \multirow{5}{*}{ Words } & ‘Grapes’' \\
\hline & & Banana & & 'Banana' \\
\hline & & Orange & & 'Orange' \\
\hline & & Carrot & & 'Carrot' \\
\hline & & Apple & & 'Apple' \\
\hline \multirow{5}{*}{ Instruction 4} & \multirow{5}{*}{ Words } & 'Pisang' & \multirow{5}{*}{ Pictures } & Grapes \\
\hline & & 'Epal' & & Banana \\
\hline & & 'Lobak Merah' & & Orange \\
\hline & & 'Oren' & & Carrot \\
\hline & & 'Anggur' & & Apple \\
\hline
\end{tabular}




\section{RESULTS}

The result of the test is analysed from understanding, accuracy and time taken for completing tasks. The results recorded based on reaction time of respondents which is in seconds (s). The reaction time of completing tasks divided by four interval of time, 1 to 30 seconds, 31 to 60 seconds, 61 to 90 seconds and exceed 90 seconds. These time interval shows an early hypothesis of the experiment, the increase the timing of participant completing the task, the higher probability participant facing difficulties to complete task. The difficulties faced by participants might be regarding their understanding of instruction given and lack of memory half-way in completing a particular tasks. Table 3 shows number of participants in completing all tasks within the time interval given.

Table 3. Number of participant response to the tasks

\begin{tabular}{lllll}
\hline Timing & Task 1 & Task 2 & Task 3 & Task 4 \\
\hline $1-30$ (Fastest) & 2 & 5 & 5 & 2 \\
$31-60$ (Slow) & 5 & 4 & 3 & 2 \\
$61-90$ (Slower) & 3 & 1 & 2 & 2 \\
$>90$ (Slowest) & 0 & 0 & 0 & 4 \\
\hline
\end{tabular}

Figure 7 shows four different graph that obtain from the Table 3 shows result obtained for all tasks had conducted. Graph (a) recorded the results for first task which ask the participants to match the flashcard by referring to picture on the given model. There are 5 out of 10 participants perform Task 1 within 31 to 60 seconds and only 2 participants successfully complete faster than others within 30 seconds. Whereas, graph (b) shows second task is matching the flashcard by referring card colour on the given model. The results had recorded 5 out 10 participants take less than half of minute $(<30$ seconds) and 4 participants takes 31 seconds to 60 seconds to complete Task 2. This is shows that ambient colours give high influence to the participant's response rather than ambient pictures in their daily activity.

On the other side, graph (c) displays that third task is placing the flashcard according of correct name of the fruit. This illustrates that 5 participants able to complete Task 3 within 30 seconds. This is demonstrating participants with Alzheimer disease have high capability to recognize what kind of pictures give to them. However, graph (d) present forth task is placing the flash card of fruit's name in Malay according of correct pictures of the fruit. The result recorded that 4 out 10 participants take more than 90 seconds and 2 participants for others time interval respectively to complete Task 4 . With this result, proved that people with Alzheimer' disease quite weak to read the Malay words and this contribute they taken longer time in order to complete a particular tasks.

As we can notice from Table 4, all participants completed Task 1 successfully. All of participants perform very well in completing Task 1, this shows that Alzheimer's people able to recognize pictures clearly. In contrast, there are participants failed to finish Task 2 , only 9 participants did perform well. This is might cause of existing of confusion while they completing Task 2 for another one participant. For Task 3 , all the participants successfully identify pictures clearly and match with word correctly. This proved that all participants did not have any problem regarding to recognize and remember pictures and picture's names in English. Lastly, Task 4 shows that it is quite difficult for them to complete it due to difficult to read and understand the word in Malay also there 3 participants are unable to read.

To summarize, all of the participants performed well in matching the flash card in Task 1 however, 5 of participants took longer time to complete the task. On the contrary, result obtained from Task 2 shows 9 participants correctly match the flash card according the instruction and 5 of them response very quick in time to complete. Therefore, we can concluded that colours is an element that can attract and influence the efficiency of Alzheimer's responses in a particular activity. This conclusion is supported by Macleod, who's concluded that performance in Stroop tasks is consistently better on congruent trials than on incongruent trials [11]. For instance, the word RED printed in red ink is congruent trials while, incongruent trials when the word RED printed in blue ink. The tasks which is involving of words for example, Task 3 and Task 4 give low effect towards participants might be due to weakness in reading. We can say words is not suitable to implement in a particular ambient system in order to deploy for Alzheimer's patients. The participants gives very positive feedback on the flashcards game. 


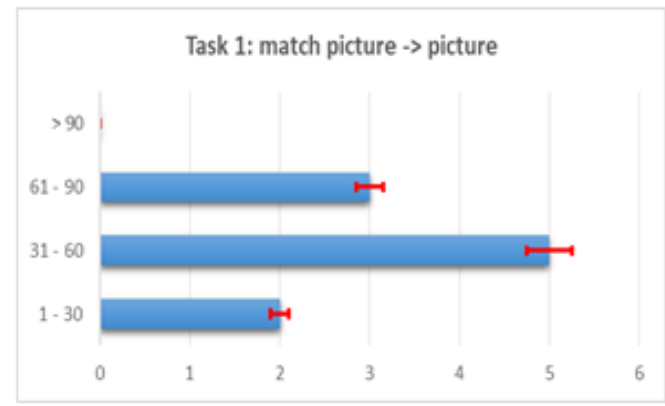

(a)

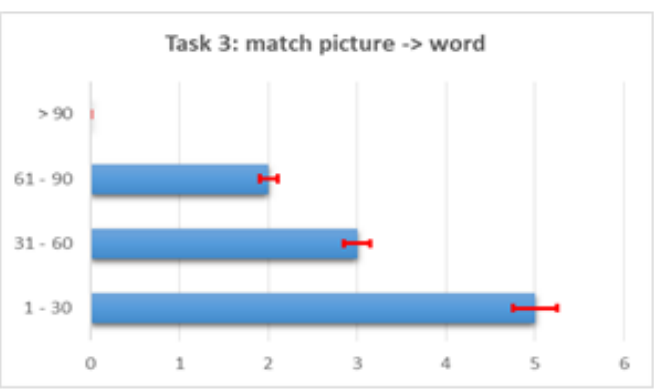

(c)

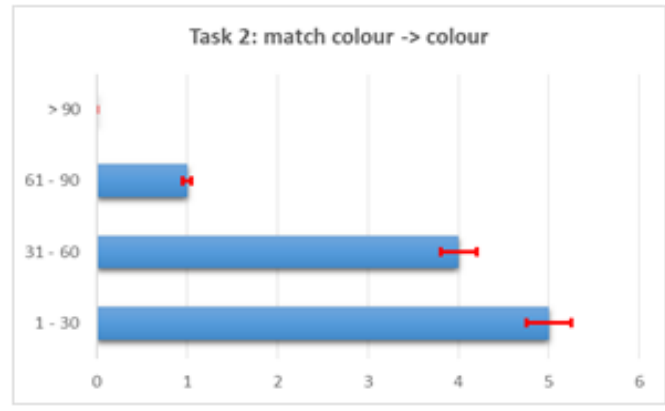

(b)

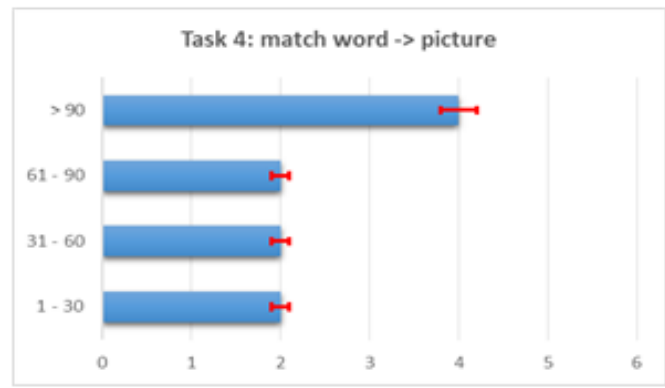

(d)

Figure 7. Results of (a) Task 1: match between pictures. (b) Task 2: match between colour card. (c) Task 3: match pictures with words. (d) Task 4: match word with pictures

Table 4. Number of participants response accurately to the instructions/task. Responses of participants to the tasks

\begin{tabular}{ccc}
\hline Task & TRUE & FALSE \\
\hline Task 1 & 10 & 0 \\
Task 2 & 9 & 1 \\
Task 3 & 10 & 0 \\
Task 4 & 5 & 5 \\
\hline
\end{tabular}

\section{CONCLUSION}

From this experiment, we concluded that patient with Alzheimer's able to understand and response toward instructions given. However, reaction time of their responses could be uncertain due to memory confusion in the middle of completing a particular task. From the result shows that responses by participants with Alzheimer's disease in particular tasks is more influenced by colours. As most of them response with less time in completing Task 2 with $90 \%$ perform within 30 seconds only. Therefore, it is suggested that in the future, the smart kitchen environment can be build based on the ambient colours, text, pictures in monitoring their activities in the area. It is also suggested that these ambient elements can assisting them of giving the right sequence of activities if they did wrong. From this experiment, obtained that studying stimulus-response compatibility related on cuing effects typically effected reaction time and error rate performance of respondents. Designing digital interfaces are increasingly being used for a variety of purposes because they have the potential to facilitate effective and efficient interactions between humans and computers by applying concepts of SRC. Human factors specialists have recognized the importance of compatibility effects in designing interfaces since the earliest days of research in the field. The overall results should help industrial developing an effective and helpful interface in machinery of ambient intelligent for assisting patients in their daily living activities especially in the kitchen environment.

\section{ACKNOWLEDGEMENT}

The author would like to acknowledge the support from Fundamental Research Grant Scheme (FRGS) under a grant number of FRGS/1/2015/ICT02/UNIMAP/01/1 [9003-00551] from the Ministry of Higher Education Malaysia. 


\section{REFERENCES}

[1] Department of Statistics Malaysia, "Department of Statistics Malaysia Official Portal," Department of Statistics, Malaysia, $2015 . \quad$ [Online]. Available: https://www.dosm.gov.my/v1/index.php?r=column/cthemeByCat\&cat=155\&bul_id=OWlxdEVoYlJCS0hUZzJyR UcvZEYxZz09\&menu_id=L0pheU43NWJwRWVSZklWdzQ4TlhUUT09. [Accessed: 05-Feb-2018].

[2] Bernama, "Senior citizens make up $2.8 \mathrm{~m}$ of Malaysia's population" The Sun Daily, 2016. [Online]. Available: http://www.thesundaily.my/news/1737046. [Accessed: 05-Feb-2018].

[3] Q. Li, W. Nan, K. Wang, and X. Liu, "Independent processing of stimulus-stimulus and stimulus-response conflicts" PLoS One, vol. 9, no. 2, pp. 1-6, 2014.

[4] O. D. Lara and M. a. Labrador, "A Survey on Human Activity Recognition using Wearable Sensors," IEEE Commun. Surv. Tutorials, vol. 15, no. 3, pp. 1192-1209, 2013.

[5] K.-Y. Lam, N. W.-H. Tsang, S. Han, J. K.-Y. Ng, S.-W. Tam, and A. Nath, "SmartMind: Activity Tracking and Monitoring for Patients with Alzheimer's Disease," 2015 IEEE 29th Int. Conf. Adv. Inf. Netw. Appl., pp. 453-460, 2015.

[6] J. P. García-Vázquez, M. D. Rodríguez, A. G. Andrade, and J. Bravo, "Supporting the strategies to improve elders' medication compliance by providing Ambient aids” Pers. Ubiquitous Comput., vol. 15, no. 4, pp. 389-397, 2011.

[7] K. Nurul, F. Ku, and C. Baber, "Ambient Cueing in Cooker Controls thru Stimulus- Response Compatibililty: Questionnaire Approach" Advcit'15, vol. 2, no. December, pp. 1-6, 2015.

[8] T. Morooka, T. Ogino, A. Takeuchi, K. Hanafusa, M. Oka, and Y. Ohtsuka, "Relationships between the color-word matching Stroop task and the Go/NoGo task: toward multifaceted assessment of attention and inhibition abilities of children" Acta Med. Okayama, vol. 66, no. 5, pp. 377-386, 2012.

[9] D. Szucs and F. Soltész, "Stimulus and response conflict in the color-word Stroop task: A combined electromyography and event-related potential study" Brain Res., vol. 1325, pp. 63-76, 2010.

[10] S. Bélanger, S. Belleville, and S. Gauthier, "Inhibition impairments in Alzheimer's disease, mild cognitive impairment and healthy aging: Effect of congruency proportion in a Stroop task" Neuropsychologia, vol. 48, no. 2, pp. 581-590, 2010.

[11] C. M. MacLeod, "Half a century of research on the Stroop effect: An integrative review" Psychol. Bull., vol. 109, no. 2, pp. 163-203, 1991. 